\title{
Postoperative opioid-prescribing patterns among surgeons and residents at university- affiliated hospitals: a survey study
}

\author{
Akash Goel, MD \\ Adina Feinberg, MD \\ Brandon McGuiness, MD \\ Sav Brar, MD \\ Sanjho Srikandarajah, MD \\ Emily Pearsall, MSc \\ Robin McLeod, MD \\ Hance Clarke, MD, PhD
}

Accepted May 14, 2019

\section{Correspondence to: \\ H. Clarke \\ Toronto General Hospital University Health Network PMB-100L, 200 Elizabeth St Toronto ON M5G 2C4 \\ hance.clarke@utoronto.ca}

DOI: $10.1503 /$ cjs. 016518

\begin{abstract}
Background: Overprescribing of opioids to patients following surgery is a public health concern, as unused pills may be diverted and contribute to opioid misuse and dependence. The objectives of this study were to determine current opioid-prescribing patterns for common surgical procedures, factors that affect surgeons' prescribing behaviour and their perceived ability to manage patients with opioid use disorder.
\end{abstract}

Methods: Survey participants included all consultant and trainee surgeons at the University of Toronto. The survey, which was administered electronically, included 52 multiple-choice, rank-order and open-text questions eliciting information on current prescribing patterns, prescribing of adjunct pain medications, and education and other factors related to opioid prescribing. Staff surgeons were also asked about how they manage patients with a suspected opioid issue.

Results: Eighty surgical trainees and 40 staff surgeons responded to the survey (response rate $32 \%$ ). Five staff surgeons (12\%) felt adequately educated to prescribe pain medications (including opioids) at discharge. Staff surgeons prescribed Tylenol 3 more frequently than other opioids. Twenty (51\%) of 39 staff surgeons reported that they sought further help for their patients when an opioid use disorder was suspected.

Conclusion: Our results support existing studies showing a large degree of variability in postoperative opioid prescribing. Institutional guidelines have been shown to be effective in curbing excessive opioid prescribing without increasing unnecessary emergency department visits for uncontrolled pain. Thus, there is an opportunity to develop institutional guidelines to educate surgical teams in the prescribing of opioids and about services available for patients with a substance use disorder.

Contexte : La surprescription d'opioïdes aux patients après une chirurgie représente un problème de santé publique car il y a un risque que les comprimés inutilisés soient détournés et utilisés à mauvais escient, voire qu'ils causent la dépendance. Cette étude avait pour objectif d'identifier les modes actuels de prescription des opioïdes pour les chirurgies courantes, les facteurs qui influent sur les habitudes de prescription des chirurgiens et leur capacité perçue à prendre en charge les cas de mésusage des opioïdes.

Méthodes : Les participants au sondage étaient tous les chirurgiens en poste et en formation à l'Université de Toronto. Ce sondage administré par voie électronique comprenait 52 questions (choix multiples, échelles ordinales et ouvertes) qui visaient à recueillir des renseignements sur les modes actuels de prescription, la prescription d'analgésiques d'appoint, l'enseignement au patient et autres éléments relatifs à la prescription des opioïdes. Les chirurgiens en poste ont aussi été interrogés sur leur gestion des cas présumés de mésusage des opioïdes.

Résultats : Quatre-vingt chirurgiens en formation et 40 chirurgiens en poste ont répondu au sondage (taux de réponse, $32 \%$ ). Cinq chirurgiens en poste (12\%) se sont estimés adéquatement renseignés sur la façon de prescrire les analgésiques, (y compris les opioïdes) au moment du congé. Les chirurgiens en poste prescrivaient Tylenol 3 fois plus souvent que d'autres opioïdes. Vingt (51\%) chirurgiens en poste sur 39 ont dit consulter s'ils avaient besoin d'aide pour la prise en charge de patients soupçonnés de présenter un problème de mésusage des opioïdes.

Conclusion : Nos résultats viennent étayer les conclusions d'études existantes selon lesquelles les modes de prescription des opioïdes en postopératoire varient grandement. Il a été démontré que l'adoption de lignes directrices institutionnelles permet de limiter efficacement la surprescription des opioïdes sans accroître indument le nombre de consultations aux urgences pour douleur non maîtrisée. Il y a donc là une possibilité d'adopter à plus grande échelle les lignes directrices institutionnelles pour sensibiliser les équipes chirurgicales à l'utilisation judicieuse des opiö̈des et à l'existence des services à l'intention des patients qui présentent un problème de mésusage. 
$\mathbf{R}$ ecent studies have highlighted the practice of overprescribing opioids to patients following surgery. ${ }^{1-3}$ This topic has received much attention owing to public concern over the opioid epidemic. Overprescribing is a public health concern, as unused pills may be diverted and used by people for whom they were not intended, contributing to the growing concern over opioid misuse and dependence. ${ }^{1-3}$ Brat and colleagues ${ }^{4}$ found that large proportions of opioid prescriptions go unused.

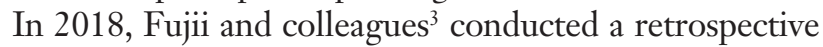
audit ( $n=10112)$ and telephoned patients who had undergone general, orthopedic or urologic surgical procedures $(n=359)$ after discharge to determine the quantity of opioids prescribed at discharge, the amount used, and whether the patients were aware of disposal strategies and nonopioid alternatives. They found that $92 \%$ of patients had received a prescription for opioids at discharge. Of the patients who used opioids, only $27 \%$ reported taking all of the prescribed opioids. Most patients (84\%) received information on the use of nonopioid strategies, including acetaminophen or nonsteroidal anti-inflammatory agents (NSAIDs), but only $18 \%$ received instructions on safe disposal of remaining opioids.

Similar results were reported by Thiels and colleagues, ${ }^{2}$ who also conducted telephone interviews with patients after discharge from surgery. Of the 2486 patients who completed the survey, $91 \%$ received a prescription for opioids at discharge, of whom $77 \%$ either did not take any or had remaining tablets. Those authors used these data to create a guideline for their affiliated hospitals.

Various institutions have sought to implement multimodal analgesia techniques in the management of postsurgical pain. Notably, the Association of Polish Surgeons implemented early nutrition, early patient activation and physiotherapy to optimize postoperative pain relief. ${ }^{5}$ This evidence-based approach reflects the changing attitudes toward multimodal management of postsurgical pain. Furthermore, it forms the basis for understanding the attitudes toward postoperative physiotherapy as a mode of pain management in our institution.

The objective of the present study was to determine current patterns of opioid prescribing for common surgical procedures, factors that affect surgeons' prescribing behaviour and their perceived ability to manage patients with a potential opioid use disorder. The ultimate goal of this research program is to create a locally tailored clinical practice guideline to reduce the amount of opioids prescribed after surgery.

\section{Methods}

\section{Best Practice in Surgery research program}

The Best Practice in Surgery program in the Department of Surgery at the University of Toronto is leading a qualityimprovement project focused on the prescribing and manage- ment of opioids after elective surgery. Members of the steering committee include surgeons, anesthesiologists and nurses, as well as surgical and anesthesiology trainees. This is a multifaceted project that includes a systematic review of the literature, ${ }^{5}$ survey of current practice at the affiliated hospitals, and development of a clinical practice guideline based on best evidence and expert consensus. In this article we report the findings of the survey of current practice, conducted in 2018.

\section{Participants}

All staff surgeons and surgical trainees from the divisions of general surgery, orthopaedic surgery, neurosurgery, thoracic surgery, plastic surgery, urology, vascular surgery and cardiac surgery associated with the University of Toronto and its 8 affiliated hospitals were invited to participate in this study.

\section{Survey design and administration}

A survey was created by a working group to obtain information on current prescribing patterns, including type and number of opioids prescribed, prescribing of adjunct pain medications, and education and other factors related to opioid prescribing. In addition, staff surgeons were asked about how they manage patients with a suspected opioid issue. The survey was initially tested by members of the steering committee to assess time to completion and clarity of questions. The working group developed the final survey after a rigorous drafting process that involved 3 in-person meetings. The survey included 52 multiple choice, rank ${ }^{1-3,5,6}$ or open-text fields (where the respondent could input the number of pills usually prescribed for specific operations). A copy of the survey is provided in Appendix 1, available at canjsurg.ca/016518-a1.

After approval from the institutional research ethics board, the survey was sent electronically by means of Novi Survey, a firewalled, encrypted online software application. Reminders were sent at 2-, 4- and 8-week intervals. Given the low response rate from surgical trainees, we converted the survey to hard copy and administered it to residents during teaching sessions in April 2018.

\section{Statistical analysis}

We generated the output and analysis for this study using SAS 9.4 (SAS Institute) for Windows. As the data on the number of opioid-containing pills prescribed at discharge for various surgical procedures were not normally distributed, we report the median number of tablets and respective interquartile ranges (IQRs).

\section{Results}

In total, 120 surgical trainees and faculty from 8 hospitals affiliated with the University of Toronto responded to the 
survey (response rate $32 \%$ ). Table 1 shows the respondents' surgical subspecialties and level of training. Responses were received from 8 surgical specialties; however, no cardiac or orthopedic surgery trainees responded to the survey. General surgeons accounted for the largest proportion of respondents (46 [38.3\%]). Overall, the demographic characteristics of the respondents were an accurate reflection of the surgical community in teaching hospitals affiliated with the University of Toronto.

Of the 40 staff surgeons, 5 (12\%) reported that they felt adequately educated to prescribe pain medications (including opioids) to surgical patients at discharge, and 29 (72\%)

\begin{tabular}{|c|c|c|}
\hline Characteristic & $\begin{array}{c}\text { Staff } \\
n=40\end{array}$ & $\begin{array}{l}\text { Residents } \\
n=80\end{array}$ \\
\hline \multicolumn{3}{|l|}{ Specialty } \\
\hline General surgery & 18/81 (22\%) & $28 / 88$ (32\%) \\
\hline Vascular surgery & $1 / 19(5 \%)$ & 9/18 (50\%) \\
\hline Urological surgery & $3 / 30(10 \%)$ & $9 / 28(32 \%)$ \\
\hline Thoracic surgery & $2 / 8(25 \%)$ & $3 / 5(60 \%)$ \\
\hline Cardiac surgery & $3 / 25(12 \%)$ & $0 / 10(0 \%)$ \\
\hline Neurosurgery & $2 / 33(6 \%)$ & $17 / 35(49 \%)$ \\
\hline Orthopedic surgery & $8 / 62(13 \%)$ & $0 / 50(0 \%)$ \\
\hline Plastic surgery & $3 / 35$ (9\%) & $14 / 29(48 \%)$ \\
\hline \multicolumn{3}{|l|}{ Year of training } \\
\hline PGY1 & - & 13 \\
\hline PGY2 & - & 17 \\
\hline PGY3 & - & 23 \\
\hline PGY4 & - & 12 \\
\hline PGY5 & - & 15 \\
\hline $\mathrm{PGY}=$ postgraduate yea & & \\
\hline
\end{tabular}

indicated that they desired more training. In contrast, 58 $(72 \%)$ of the 80 surgical trainees regarded their education about analgesic prescription at discharge to be adequate, and $16(20 \%)$ indicated a desire for additional education.

When asked about the most influential factors that affect their prescribing patterns, surgical trainees felt that staff surgeons were the most influential factor. Staff, on average, ranked prior habits as the factor most influencing their prescribing. Habits was the second most important factor for residents, and opinion leaders was the next highest ranked factor in both groups after habits. Staff surgeons and trainees also agreed that educational seminars and medical school education did not influence their prescribing patterns. Last, both groups ranked peers and clinical practice guidelines as moderate influences, although staff surgeons ranked guidelines slightly higher than peers, and surgical trainees ranked peers slightly higher than guidelines.

Hydromorphone, Percocet (oxycodone-acetaminophen, Endo Pharmaceuticals) and Tylenol 3 (acetaminophencodeine, McNeil Consumer Healthcare) were the most common opioids prescribed at discharge by both staff and trainee surgeons (Fig. 1). Resident trainees prescribed hydromorphone more frequently than Percocet and Tylenol 3, whereas staff surgeons prescribed Tylenol 3 more frequently than Percocet and hydromorphone. Morphine was the fourth most frequently prescribed opioid at discharge for both groups, and staff surgeons also prescribed codeine and tramadol.

Regarding adjunct analgesics for patients having various types of surgery, acetaminophen was prescribed by at least $50 \%$ of all surgeons, but close to $30 \%$ of vascular, plastic and urologic surgeons said they never prescribe acetaminophen (Fig. 2). There were also variations, depending on

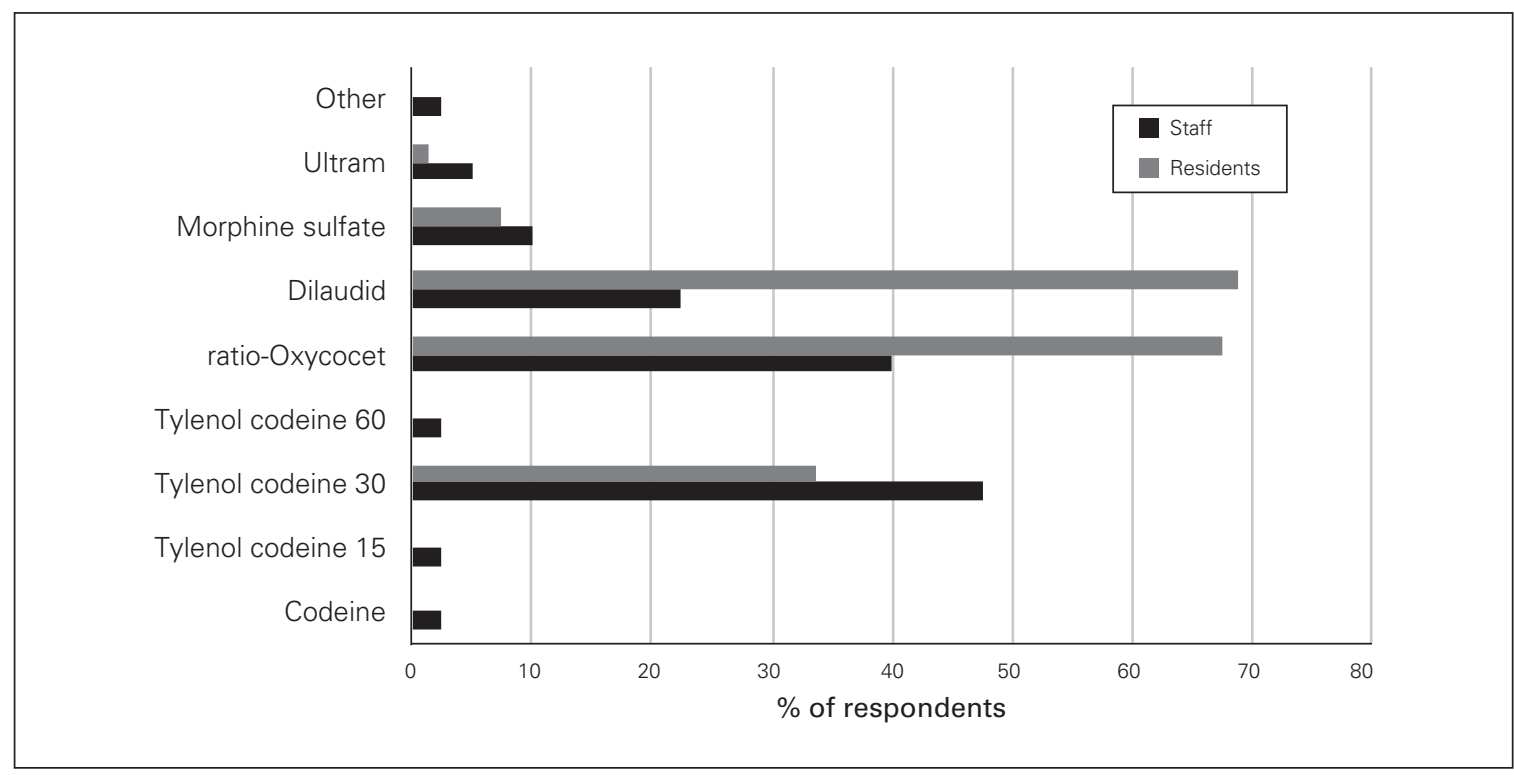

Fig. 1. Discharge prescription opioid preferred by staff and resident surgeons. ratio-Oxycocet $=$ oxycodoneacetaminophen, Endo Pharmaceuticals; Tylenol = acetaminophen-codeine, McNeil Consumer Healthcare; Ultram = tramadol, Janssen Pharmaceuticals. 
the surgical procedure, in the proportion of surgeons who prescribed gabapentin/pregabalin, NSAIDs and physiotherapy on discharge (Figs. 3-5).

The highest number of opioid-containing tablets prescribed was for patients who had open laparotomy or total knee arthroplasty, whereas patients having various urologic procedures or diagnostic procedures by thoracic surgeons were prescribed lower amounts of tablets (Table 2). Wide IQRs (> 10 opioid-containing tablets) were observed among all surgeons, but especially for laparoscopic cases.

Cardiac surgeons appeared to consistently prescribe a median of 30 (IQR 30-50) opioid-containing tablets at discharge following coronary artery bypass grafting and open valve replacement. Similarly, general surgeons stated that they prescribe a median of 20 opioid-containing tablets on discharge following laparoscopic and breast procedures, but 30 tablets for open laparotomy. Compared to their general surgery counterparts, urologic surgeons appeared to prescribe fewer opioid-containing tablets for laparoscopic cases (nephrectomy) (median 17.5, IQR 10-25) and open cases (prostatectomy) (median 20, IQR 17-25). Plastic surgeons stated that they prescribe a median of 20 (IQR 20-30) opioid-containing tablets after breast augmentation and 30 (IQR 25-35) tablets after breast reconstruction with latissimus dorsi flap. Neurosurgeons reported prescribing a median of 20 opioid-containing tablets for patients following craniotomy and minicraniotomy, and they did not change their prescription practices between bi-/trilevel (median 30, IQR 25-30) and multilevel (> bi-/trilevel) (median 30, IQR 30-30) decompression and fusion procedures. Vascular

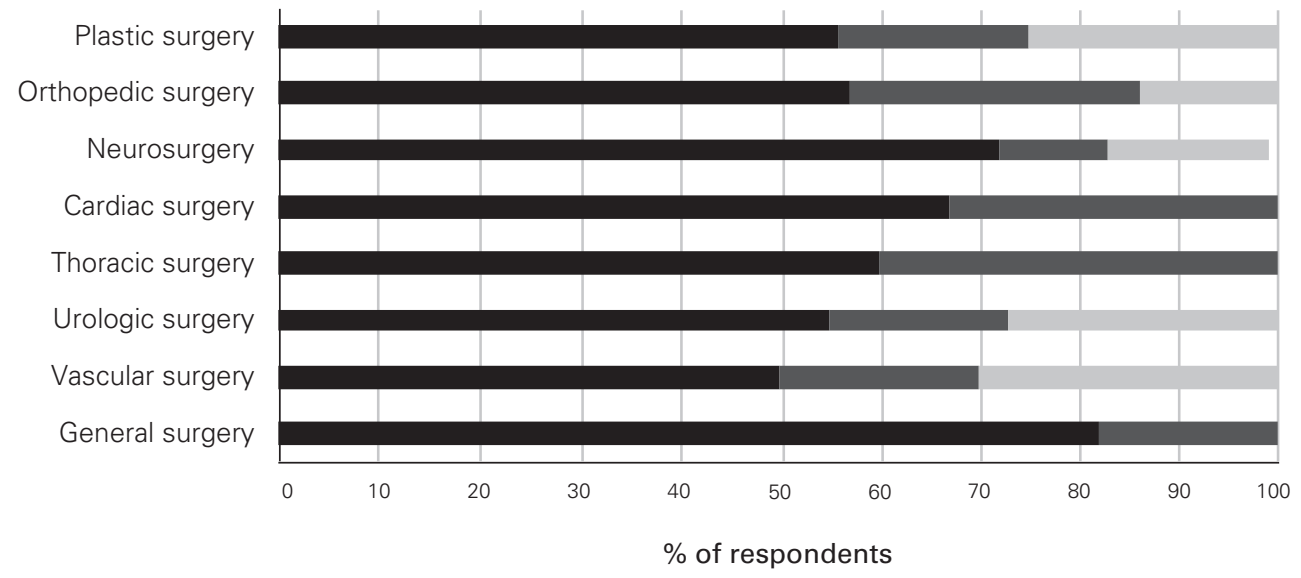

Always Sometimes Never

Fig 2. Frequency of prescribing of acetaminophen on discharge by surgical subspecialty.

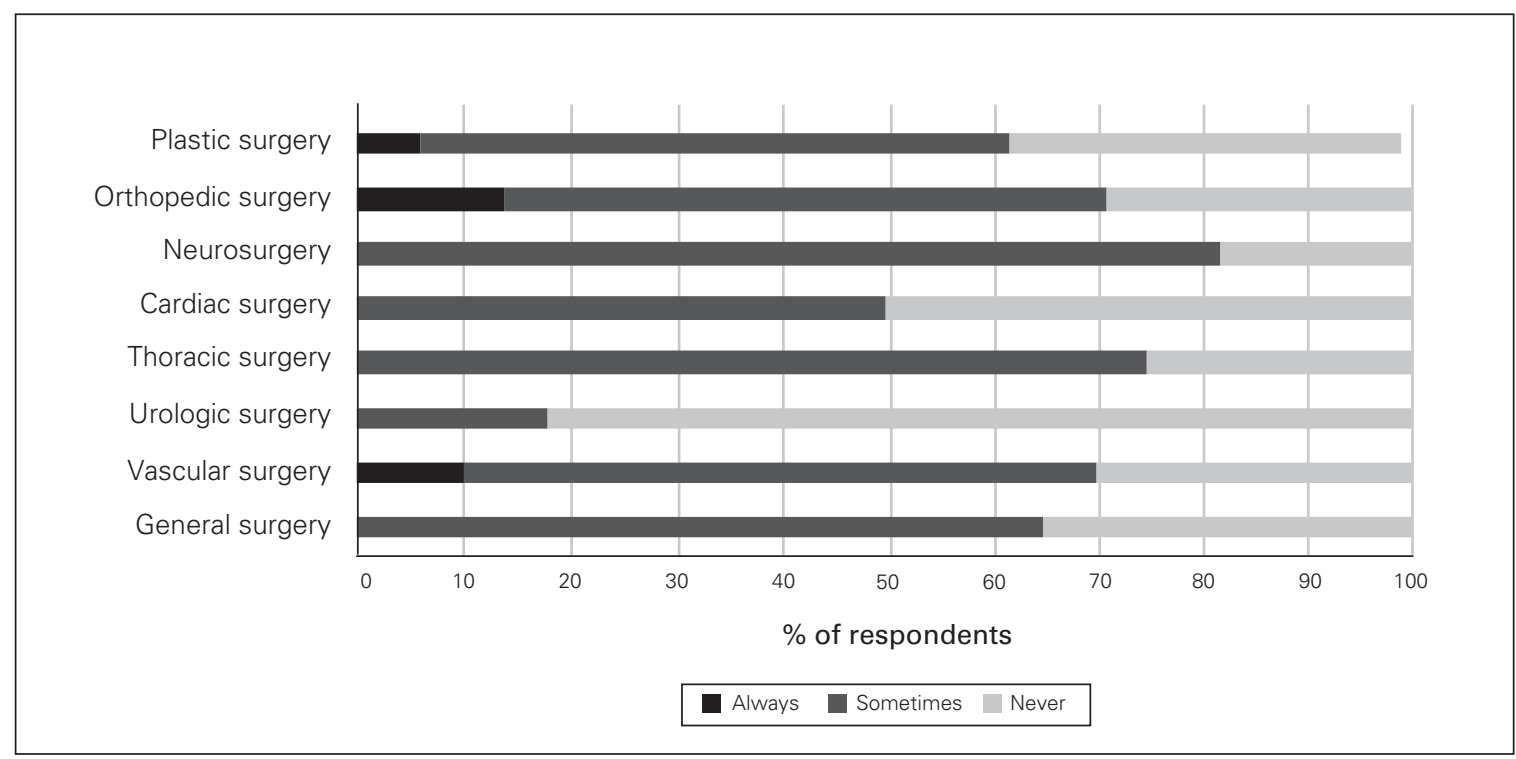

Fig. 3. Frequency of prescribing of gabapentin/pregabalin on discharge by surgical subspecialty. 
surgeons seemed to prescribe higher numbers of opioidcontaining tablets for open abdominal aortic aneurysm repair (median 30, IQR 30-30) than for endovascular aortic aneurysm repair (median 17.5, IQR 10-20). Thoracic surgeons reported prescribing similar numbers of opioidcontaining tablets for mediastinoscopy (median 10, IQR 0-10), pleural aspiration and biopsy (median 10, IQR 0-25) and chest tube placement (median 15, IQR 5-30). However, they stated that they prescribe more tablets for video-assisted thoracoscopic surgery (median 50, IQR 20-60), esophagectomy (median 60, IQR 30-60) and thoracotomy (median 60, IQR 60-60). Finally, orthopedic surgeons reported prescribing varying numbers of opioid-containing tablets for different knee procedures, including diagnostic knee arthroscopy (median 30, IQR 15-35), arthroscopic anterior cruciate ligament repair (median 60, IQR 50-60) and total knee replacement (median 80, IQR 80-100). The median number of tablets prescribed after hip replacement was similar to that after total knee replacement, whereas patients having shoulder arthroscopy were prescribed a median of 60 (IQR 30-60) tablets.

Thirty-nine staff surgeons responded to questions on their perceptions of opioid-related disorders. They felt that an opioid use disorder or addiction disorder develops in $9 \%$ (standard deviation $8.5 \%$ ) of patients after surgery. When patients return for a refill of their opioid prescription, 23 surgeons $(59 \%)$ said that they discuss the reasons for the need for additional analgesic therapy when the request is made within 30 days of surgery, and 9 surgeons (23\%) reported that they refill the prescription without further discussion.

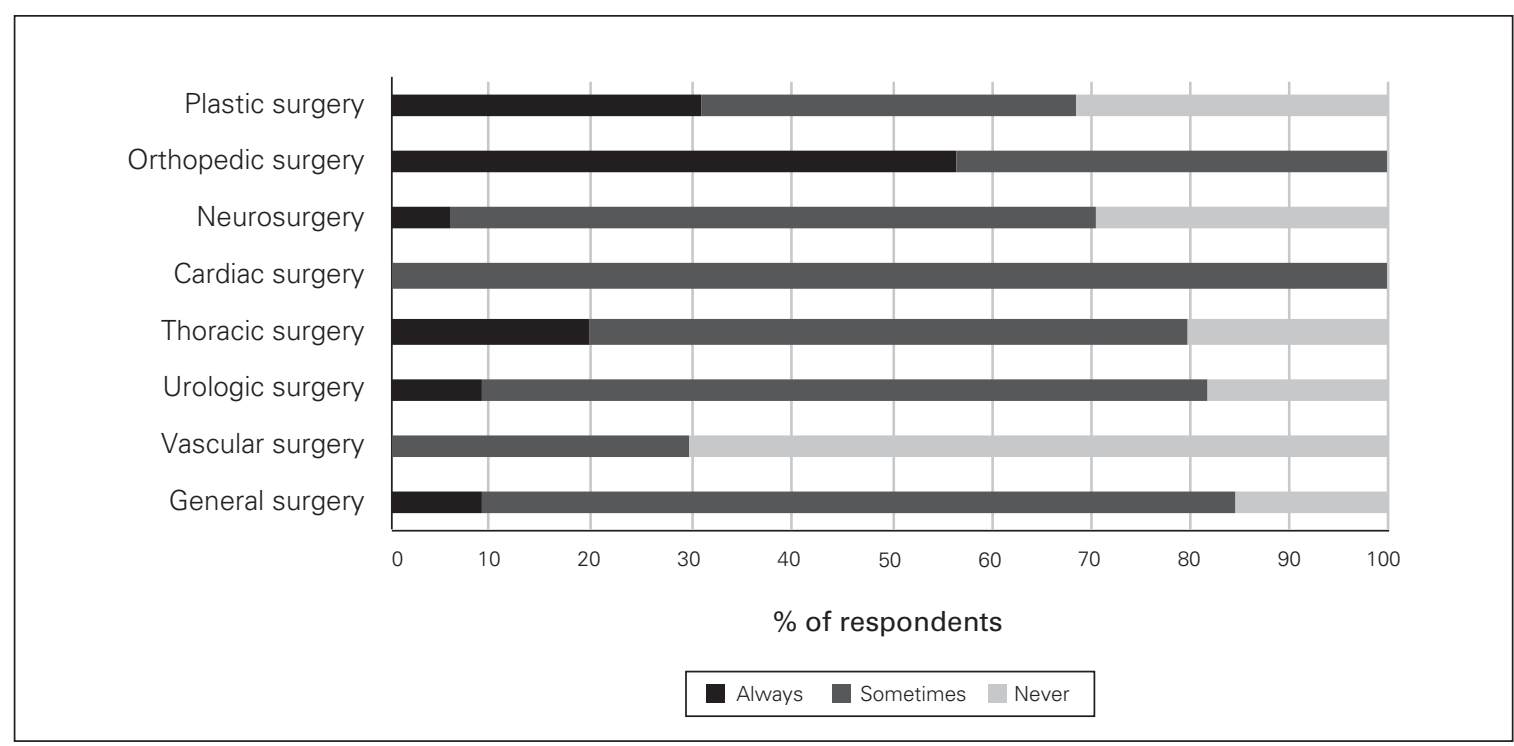

Fig. 4. Frequency of prescribing of nonsteroidal anti-inflammatory agents on discharge by surgical subspeciality.

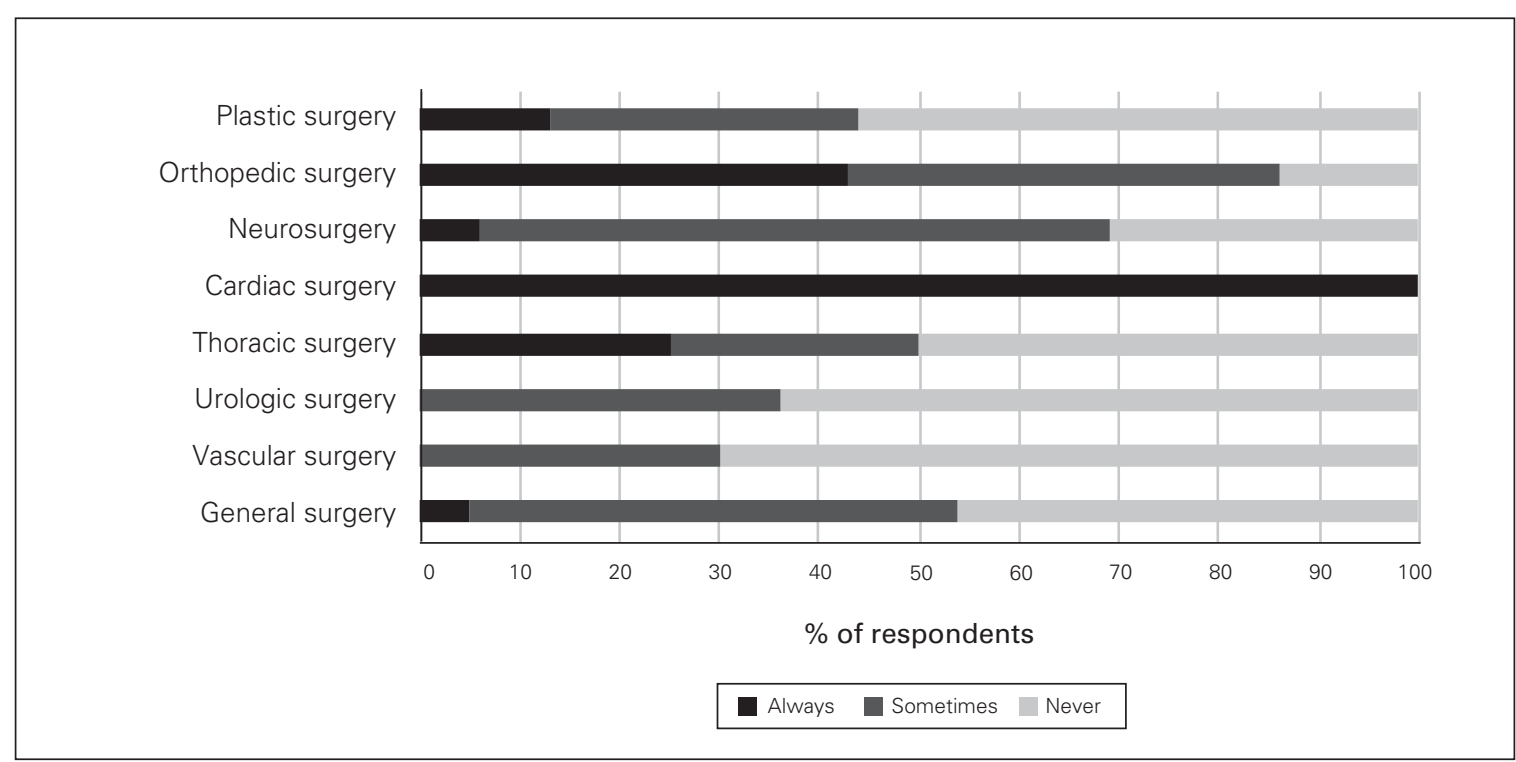

Fig. 5. Frequency of prescribing of physiotherapy on discharge by surgical subspeciality. 
Table 2. Number of opioid-containing tablets prescribed at discharge for various surgical procedures

\begin{tabular}{|c|c|c|c|}
\hline \multirow[b]{2}{*}{ Surgical specialty; procedure } & \multirow{2}{*}{$\begin{array}{l}\text { No. of } \\
\text { respondents }\end{array}$} & \multicolumn{2}{|c|}{ No. of tablets } \\
\hline & & Median (IQR) & Range \\
\hline \multicolumn{4}{|l|}{ Cardiac surgery } \\
\hline Coronary artery bypass grafting & 3 & $30(30-50)$ & $30-50$ \\
\hline Open valve replacement & 3 & $30(30-50)$ & $30-50$ \\
\hline \multicolumn{4}{|l|}{ General surgery } \\
\hline Laparoscopic cholecystectomy & 43 & $20(15-30)$ & $6-30$ \\
\hline Laparoscopic appendectomy & 44 & $20(15,30)$ & $6-30$ \\
\hline Lumpectomy + sentinel lymph node biopsy & 38 & $20(12-30)$ & $0-60$ \\
\hline Mastectomy + sentinel lymph node biopsy & 38 & $20(20-30)$ & $10-90$ \\
\hline Open inguinal hernia repair & 43 & $20(15-30)$ & $6-60$ \\
\hline Laparoscopic inguinal hernia repair & 38 & $20(15-30)$ & $4-30$ \\
\hline Laparoscopic surgery (inpatient stay) & 43 & $20(10-30)$ & $0-90$ \\
\hline Open laparotomy (inpatient stay) & 44 & $30(20-30)$ & $8-120$ \\
\hline \multicolumn{4}{|l|}{ Neurosurgery } \\
\hline Microdiscectomy (herniated disc) & 18 & $20(15-20)$ & $10-40$ \\
\hline $\begin{array}{l}\text { 2- to 3-level posterior cervical discectomy with } \\
\text { fusion }\end{array}$ & 18 & $30(25-30)$ & $20-45$ \\
\hline Multilevel disc fusion & 18 & $30(30-30)$ & $20-80$ \\
\hline Minicraniotomy & 18 & $20(15-24)$ & $0-60$ \\
\hline Craniotomy & 18 & $20(20-30)$ & $0-60$ \\
\hline Microvascular decompression of cranial nerve VII & 18 & $20(20-30)$ & $10-60$ \\
\hline Transphenoidal surgery & 17 & $20(15-25)$ & $0-40$ \\
\hline \multicolumn{4}{|l|}{ Plastic surgery } \\
\hline Single-digit reimplantation & 14 & $30(25-30)$ & $20-50$ \\
\hline Breast augmentation & 15 & $20(20-30)$ & $10-42$ \\
\hline Breast reconstruction with latissimus dorsi flap & 16 & $30(25-35)$ & $20-42$ \\
\hline Dupuytren contracture release & 16 & $24(20-30)$ & $10-40$ \\
\hline Carpal tunnel release & 16 & $18(10-20)$ & $0-28$ \\
\hline \multicolumn{4}{|l|}{ Thoracic surgery } \\
\hline Video-assisted thoracoscopic surgery & 5 & $50(20-60)$ & $20-60$ \\
\hline Mediastinoscopy & 5 & $10(0-10)$ & $0-20$ \\
\hline Pleural aspiration and biopsy & 4 & $10(0-25)$ & $0-30$ \\
\hline Esophagectomy & 5 & $60(30-60)$ & $30-100$ \\
\hline Thoracotomy & 5 & $60(60-60)$ & $30-100$ \\
\hline Chest tube placement & 4 & $15(5-30)$ & $0-40$ \\
\hline Bronchoscopy & 5 & $0(0-0)$ & $0-0$ \\
\hline \multicolumn{4}{|l|}{ Urology } \\
\hline $\begin{array}{l}\text { Extracorporeal shock wave lithotripsy } \\
\text { (stone) }\end{array}$ & 9 & $15(10-15)$ & $0-30$ \\
\hline $\begin{array}{l}\text { Extracorporeal shock wave lithotripsy } \\
\text { (vasectomy) }\end{array}$ & 3 & $10(0-15)$ & $0-15$ \\
\hline Transurethral resection of bladder tumour & 12 & $5(2-10)$ & $0-15$ \\
\hline Laparoscopic nephrectomy & 12 & $18(10-25)$ & $10-30$ \\
\hline Open prostatectomy & 12 & $20(17-25)$ & $10-30$ \\
\hline \multicolumn{4}{|l|}{ Vascular surgery } \\
\hline Endovascular aortic aneurysm repair & 10 & $18(10-20)$ & $0-30$ \\
\hline Open abdominal aortic aneurysm repair & 9 & $30(30-30)$ & $20-30$ \\
\hline Arteriovenous fistula creation & 10 & $10(10-10)$ & $0-20$ \\
\hline Femoral/popliteal bypass & 10 & $20(20-30)$ & $15-30$ \\
\hline Carotid endarterectomy & 10 & $12(10-20)$ & $0-20$ \\
\hline \multicolumn{4}{|l|}{ Orthopedic surgery } \\
\hline Diagnostic knee arthroscopy & 4 & $30(15-35)$ & $0-40$ \\
\hline Arthroscopic anterior cruciate ligament repair & 4 & $60(50-60)$ & $40-60$ \\
\hline Total knee replacement & 6 & $80(80-100)$ & $60-120$ \\
\hline Total hip replacement & 6 & $80(80-100)$ & $40-100$ \\
\hline $\begin{array}{l}\text { Shoulder arthroscopy - examination under } \\
\text { anesthesia }\end{array}$ & 4 & $60(30-60)$ & $0-60$ \\
\hline $\begin{array}{l}\text { Removal of elbow plates/screws - } \\
\text { general anesthesia }\end{array}$ & 5 & $40(40-60)$ & $30-60$ \\
\hline $\begin{array}{l}\text { Resection arthroplasty/arthrodesis (hammer toe } \\
\text { deformity) }\end{array}$ & 3 & $60(40-90)$ & $40-90$ \\
\hline Open reduction internal fixation hand & 4 & $35(15-50)$ & $0-60$ \\
\hline $\mathrm{IQR}=$ interquartile range & & & \\
\hline
\end{tabular}

Nineteen surgeons (44\%) stated that, when an opioid misuse problem is suspected, they tend to prescribe lower dosages of opioids, and 18 (46\%) said they cease opioid prescribing altogether. Twenty surgeons $(51 \%)$ said they send their patient for help in such cases, and 15 (38\%) stated that they do not know what to do. Twentytwo surgeons $(56 \%)$ reported that they were not aware of programs that can help their patients if they suspect an opioid or alcohol problem, and 5 (13\%) felt that these services are easy to access.

\section{Discussion}

Previous investigators aimed to develop opioid-prescribing protocols using retrospective data collection from medical and pharmacy records as well as patient questionnaires. Our survey focused on the prescribing patterns of surgical consultants and trainees in 8 different subspecialties and multiple academic teaching hospitals, ensuring diversity of experience and care delivery in our response set. We found variations in opioid-prescribing patterns after common surgical procedures among surgeons based on training stage and surgical subspecialty. Previous reports have also shown significant variations in the number of opioid-containing tablets prescribed after a variety of procedures. ${ }^{6-10}$

These variations can be explained by perceptions among surgical providers that different patients need different amounts of opioids (patient-centred variation). ${ }^{10}$ Furthermore, patients may rate the quality of care they receive based on the amount of surgical pain they experience. Awareness of publicly available physician ratings may nudge surgical providers to become more generous with their opioid prescriptions. In addition, some authors have suggested that restrictions on opioid prescribing may "paradoxically" result in overprescribing. ${ }^{11}$ Surgeons may overcome the inability to renew opioid prescriptions remotely by writing inappropriately high prescriptions. ${ }^{11}$

In the current study, residents felt more adequately trained to prescribe opioids than staff surgeons, likely not realizing that their prescribing habits are influenced by their superiors. This is in keeping with 
the results of a recent study in which $95.2 \%$ of surgical residents reported that attending preference influenced their prescription practice. ${ }^{12}$ However, in the present study, both residents and attending surgeons indicated that they require more education on safe opioid-prescribing practices at discharge and on opioid management.

Our findings also confirm existing data showing that Tylenol 3, Percocet and Dilaudid (hydromorphone, Rhodes Pharma) continue to be the most frequently prescribed opioids in Canada. ${ }^{13}$ Among staff surgeons, Tylenol 3 was the most frequently prescribed opioid, whereas among surgical residents, the preferred opioid was hydromorphone, possibly owing to the influence of acute pain services' use of hydromorphone in patient-controlled analgesia for postoperative pain. In contrast, attending surgeons tend to be more strongly influenced by previous practice patterns. Although there has been a shift toward encouraging prescribing of hydromorphone (over Tylenol 3) owing to its safety profile and more homogeneous metabolism, attending surgeons' practice patterns are more challenging to modify than those of their junior counterparts. ${ }^{13}$

We also observed variability in prescribing of adjunct analgesia medications in the postoperative period. Apart from cardiac, thoracic and vascular surgeons, a proportion of surgeons reported never prescribing acetaminophen. The larger variability in gabapentin/pregabalin prescribing can likely be attributed to differences in pain patterns between surgical populations. For example, orthopedic, plastic, vascular and neurologic surgery patients are more likely than other surgical patients to experience medical and/or surgical neuropathic pain. The variation in postoperative prescribing of NSAIDs may also be due to patient factors. For example, vascular surgery patients often are elderly and diabetic, have preexisting renal disease and receive contrast intravenously during admission, which puts them at risk for postoperative renal dysfunction. This may cause concern that NSIAD use in such patients will lead to further renal dysfunction. Similarly, cardiac and orthopedic surgery patients almost universally receive postoperative rehabilitation regimens. Given the increasing evidence that NSAIDs do not increase surgical bleeding and the fact that multimodal analgesia is readily available, there is increasing evidence to support its use in the postoperative period. ${ }^{14}$ General surgeons' reticence to prescribe NSAIDs postoperatively may be explained by the ongoing debate about NSAID-induced anastomotic leaks in patients who have undergone bowel surgery. ${ }^{15}$ Reticence to prescribe NSAIDs among orthopedic surgeons and neurosurgeons can be attributed to the limited evidence of risk of nonunion and pseudoarthrosis after spine surgery. ${ }^{15}$ Therefore, future guidelines will need to incorporate the differences in patient populations when making recommendations regarding prescribing opioids after discharge.

Our survey results are consistent with those of other studies showing that surgeons account for a large degree of the variability observed in opioid-prescribing patterns., ${ }^{9,14}$ Individual surgeons may vary their prescriptions for the same procedure irrespective of patient factors..$^{15}$ Emerging evidence suggests that the median duration of opioid treatment should be 4-9 days for general surgery procedures and 6-15 days for musculoskeletal procedures, ${ }^{15}$ although a 7-day limit on the initial opioid prescription may be adequate for most procedures. Hill and colleagues ${ }^{10}$ recommended that 5 opioid-containing pills be prescribed for partial mastectomy and that 10 pills be prescribed for partial mastectomy with sentinel lymph node biopsy. Our survey results indicate that there is variation in prescription patterns (10-90 tablets) between these 2 procedures but that this range still exceeds the recommended limits. Furthermore, the Michigan Opioid Prescribing Engagement Network (OPEN) recommends that $10-15$ opioidcontaining tablets be prescribed after appendectomy, cholecystectomy and inguinal hernia repair. ${ }^{16}$ This recommendation was exceeded by the surgeons in our survey, who stated they would prescribe a median of 20 opioidcontaining tablets on discharge in these cases. Bartels and colleagues $^{17}$ found that $45 \%$ of thoracic surgery patients consumed fewer than 5 opioid-containing tablets, whereas the median number of tablets prescribed by the thoracic surgeons in our survey ranged from 0 to 60 . These discrepancies once again show a lack of uptake of emerging evidence regarding patients' postoperative analgesic needs.

Importantly, the surgeons in our study desired access to education about resources for their patients. Given that $56 \%$ of surgeons were not aware of programs that can help their patients if they suspect an opioid or alcohol problem and only $13 \%$ believed that services for patients with substance use disorders are easy to access, there is an opportunity to educate surgical teams on the services available for patients with suspected substance use disorders. Transitional pain teams have been developed at some institutions to handle patients with complex pain conditions with or without opioid use disorder. ${ }^{18}$ This model could be replicated at other institutions to assist surgeons in dealing with this complex issue.

As research into postoperative prescribing practices continues, it would be worthwhile to examine the differences in prescribing patterns between countries and continents. Understanding whether physicians discuss preferred opioids with their patients might be useful in determining who best to create educational tools. Postoperative education in this area has been lacking, and it would be important to gauge the amount of education prescribers and patients receive with respect to prescribing practices on discharge.

\section{Limitations}

Limitations of our study include a low response rate, with limited responses from attending surgeons. Although the responses suggested that trainee prescribing habits are more 
dependent on attending prescribing habits than other factors, future studies should aim to engage attending surgeons. Furthermore, the $32 \%$ response rate makes extrapolation of our results challenging. Our survey methodology has limitations. The use of the term "opioid-containing tablet" does not completely capture the variety in opioid prescribing (i.e., dosage, strength). However, given the wide range of prescribing habits among surgeons at the University of Toronto (i.e., different opioids, different strengths), this was the most optimal survey design to be able to capture attitudes toward postsurgical prescribing habits. There are inherent pitfalls in survey methodology, especially when asking about practice habits among various subspecialists who perform a wide range of surgical procedures that are not necessarily comparable in terms of postoperative pain, mobility and rehabilitation requirements. Last, although this survey was done at a single institution, we believe that there is substantial practice variation between surgical centres within the University of Toronto that allowed us to more appropriately capture surgical attitudes toward this important issue.

\section{CONCLUSION}

The results of our survey support existing data showing that there is a large degree of variability in postoperative opioid prescribing. Institutional guidelines have been shown to be effective in curbing excessive opioid prescribing without increasing unnecessary emergency department visits for uncontrolled pain. ${ }^{19}$ Thus, there is an opportunity to develop institutional guidelines to educate surgical teams on prescribing of opioid-containing pills and also about services available for their patients with substance use disorder. It is our intention to also use the findings from this survey regarding factors that influence prescribing patterns to help with the implementation of a guideline. As both staff and trainees felt that peers and clinical practice guidelines were influential factors, we will ensure that we encourage the use of peer-to-peer education and active dissemination of the guideline to help with uptake. We hope that this will affect habits, which was the most important influential factor.

Affiliations: From the Department of Anesthesia, University of Toronto, Toronto, Ont. (Goel); the Harvard T.H. Chan School of Public Health, Boston, Mass. (Goel, McGuiness); the Department of Surgery, University of Toronto, Toronto, Ont. (Feinberg, Brar, Pearsall, McLeod); the Department of Vascular Surgery, McMaster University, Hamilton, Ont. (McGuiness); the Department of Surgery, Mount Sinai Hospital, Toronto, Ont. (Brar); the Department of Anesthesia, North York General Hospital, Toronto, Ont. (Srikandarajah); and the Department of Anesthesia, University Health Network, Toronto, Ont. (Clarke).

Competing interests: None declared.

Contributors: A. Goel, A. Feinberg, S. Brar, S. Srikandarajah, E. Pearsall, R. McLeod and H. Clarke designed the study. A. Goel acquired the data, which A. Goel, B. McGuiness, S. Brar, E. Pearsall, R. McLeod and H. Clarke analyzed. A. Goel, E. Pearsall, R. McLeod and H. Clarke wrote the article, which all authors reviewed and approved for publication.

\section{References}

1. Habermann EB. Are opioids overprescribed following elective surgery? Adv Surg 2018;52:247-56.

2. Thiels CA, Ubl DS, Yost KJ, et al. Results of a prospective, multicenter initiative aimed at developing opioid-prescribing guidelines after surgery. Ann Surg 2018;268:457-68.

3. Fujii MH, Hodges AC, Russell RL, et al. Post-discharge opioid prescribing and use after common surgical procedure. 7 Am Coll Surg 2018;226:1004-12.

4. Brat G, Agniel D, Beam A, et al. Post-surgical opioid prescription duration and the association with overdose and abuse. 7 Am Coll Surg 2017;225(4 Suppl 2):e29.

5. Wordliczek J, Zajaczkowska R, Dziki A, et al. Postoperative pain relief in general surgery - recommendations of the Association of Polish Surgeons, Polish Society of Anaesthesiology and Intensive Therapy, Polish Association for the Study of Pain and Polish Association of Regional Anaesthesia and Pain Treatment. Pol Przegl Chir 2019;91:47-68.

6. Feinberg AE, Chesney TR, Srikandarajah S, et al.; Best Practice in Surgery Group. Opioid use after discharge in postoperative patients: a systematic review. Ann Surg 2018;267:1056-62.

7. Rodgers J, Cunningham K, Fitzgerald K, et al. Opioid consumption following outpatient upper extremity surgery. 7 Hand Surg Am 2012; $37: 645-50$.

8. Mutlu I, Abubaker O, Laskin DM. Narcotic prescribing habits and other methods of pain control by oral and maxillofacial surgeons after impacted third molar removal. 7 Oral Maxillofac Surg 2013;71: 1500-3.

9. Stanek JJ, Renslow MA, Kalliainen LK. The effect of an educational program on opioid prescription patterns in hand surgery: a quality improvement program. 7 Hand Surg Am 2015;40:341-6.

10. Hill M, McMahon ML, Stucke RS, et al. Wide variation and excessive dosage of opioid prescriptions for common general surgical procedures. Ann Surg 2017;265:709-14.

11. Blay E, Nooromid MJ, Bilimoria KY, et al. Variation in postdischarge opioid prescriptions among members of a surgical team. Am 7 Surg 2018;216:25-30.

12. Theisen K, Jacobs B, Macleod L, et al. The United States opioid epidemic: a review of the surgeon's contribution to it and health policy initiatives. BfU Int 2018;122:754-9.

13. Chiu AS, Healy JM, DeWane MP, et al. Trainees as agents of change in the opioid epidemic: optimizing the opioid prescription practices of surgical residents. 7 Surg Educ 2017;75:65-71.

14. Alam A, Juurlink D. The prescription opioid epidemic: an overview for anesthesiologists. Can $\mathcal{F}$ Anaesth 2016;63:61-8.

15. Wick EC, Grant MC, Wu CL. Postoperative multimodal analgesia pain management with nonopioid analgesics and techniques: a review. FAMA Surg 2017;152:691-7.

16. Opioid Prescribing Engagement Network. Prescribing recommendations. Available: https://opioidprescribing.info/ (accessed 2017 Oct. 27).

17. Bartels K, Mayes L, Dignmann C, et al. Opioid use and storage patterns by patients after hospital discharge following surgery. PLoS One 2016;11:e0147972.

18. Katz J, Weinrib A, Fashler SR, et al. The Toronto General Hospital Transitional Pain Service: development and implementation of a multidisciplinary program to prevent chronic postsurgical pain. $\mathcal{f}$ Pain Res 2015;8:695-702.

19. Wetzel M, Hockenberry J, Raval MV. Interventions for postsurgical opioid prescribing: a systematic review. FAMA Surg 2018;153: 948-54. 